\title{
К ВОПРОСУ ОБ УПРАВЛЕНИЯ КОНКУРЕНТОСПОСОБНОСТЬЮ ПЕРСОНАЛА ПРЕДПРИЯТИЯ
}

\section{(c) 2021 Шакирьянова Алсу Ильдаровна}

кандидат экономических наук, доцент кафедры управления человеческими ресурсами Казанский (Приволжский) федеральный университет, Россия, Казань

E-mail: AIShakiryanova@kpfu.ru

\section{(c) 2021 Фатхуллин Альберт Рашитович}

кандидат экономических наук, ассистент кафедры управления человеческими ресурсами Казанский (Приволжский) федеральный университет, Россия, Казань

E-mail:2512252@gmail.com

\section{(c) 2021 Мухаметшин Дамир Фаридович}

кандидат экономических наук, доцент кафедры управления человеческими ресурсами Казанский (Приволжский) федеральный университет, Россия, Казань

E-mail: DFMuhametshin@kpfu.ru

Актуальность статьи заключается в том, что в современных условиях развития экономических отношений конкуренция между предприятиями всех форм собственности возрастает интенсивными темпами. Одним из факторов производства являются трудовые ресурсы. Как отмечают эксперты, важно учитывать корреляцию между конкурентоспособностью трудовых ресурсов и оценочными результатами предприятия. В условиях глобализации хозяйственных отношений управление конкурентоспособностью трудовых ресурсов является фактором успеха.

Ключевые слова: управление, персонал, конкурентоспособность предприятия, управление конкурентоспособностью трудовых ресурсов, проблемы конкурентоспособности предприятия, пути повышения конкурентоспособности персонала, факторы конкурентоспособности персонала, качество персонала.

Нынешние суровые конкурентные условия остро ставят проблему повышения конкурентоспособности предприятия. Объективная потребность всех экономических субъектов, стремящихся к регулярному развитию и поддержанию стабильной ситуации, заключается в разработке стратегии повышения конкурентоспособности бизнеса. Быстро меняющиеся рыночные условия требуют быстрой реакции и адаптации, заставляя руководство предприятия приобретать современные методы и инструменты для обеспечения и повышения конкурентоспособности бизнеса. Для решения проблем повышения конкурентоспособности предприятия предложены основные мероприятия.

Неотъемлемым условием работы в рыночной экономике является конкуренция. Дословно данный термин определяется как сталкивание, соперничество, непрекращающаяся гонка (рисунок 1). Конкурентоспособность предприятия подразумевает возможность обеспечить предлагаемой продукции лучшие условия реализации и сбыта, а также и потребления клиен- там. Такое определение наиболее просто и емко отражает сущность исследуемой категории.

Вклад в изучение конкуренции внесли представители зарубежных экономических школ. К примеру, Й.Шумпетер, считал, что конкурентный дух соперничества присущ предпринимателю с инновационным складом ума. Конкуренция формируется и присуща только предпринимательской среде, а не иным типам хозяйствования. Соответственно, основными показателями для оценки конкуренции, исходя из его научных трудов, будут выступать качественные показатели - это личностные способности, это инновационные технологии, это нестандартность сбытовой политики, интуитивные и экспертные знания отрасли и хозяйственных процессов и др. В трудах мыслителя также прослеживается радикальный подход к построению бизнеса, так называемый процесс «созидательного разрушения».

В трудах ученого подчеркивается, что базисом и основой конкурентной борьбы является внедрение инноваций предпринимателем, процесс «созидательного разрушения». Предприни- 
матель характеризуется определенной уникальной мотивацией, которая позволяет действовать в условиях недостатка информации, и несмотря на проблемы и трудности, такой конкурентоспособный уникум - личность легко преодолевает различного рода трудности.

Предприниматель по мнению ученого Й.Шумпетера представляет собой уникального человека с выдающимися личностными характеристиками, прежде всего, лидера - инноватора.

В трудах Адама Смита конкуренция определяется, прежде всего, как «гонка», и, в первую очередь, гонка за сбыт между продавцами в случае чрезмерного предложения, либо гонка между покупателями за редким и нужным товаром. Таким образом, в классической политэкономии конкуренция определяется как реакция участников рынка, в свою очередь, конкурентоспособность участника рынка или отрасли определяется как возможность противостоять внешним факторам.

В качестве определяющих факторов определены свобода выбора действий, наличие необходимого количества участников рынка, отсутствие монополии, равные условия действий на рынке, временные ограничения, знания о принципах и механизме рынка.

В современной экономике сущность конкуренции определяется в широком смысле этого явления, как возможности, условия деятельности, и оценивается прежде всего комплексно. Таким образом, в конкурентной борьбе в условиях рыночной экономики сталкиваются имеющиеся предпринимательские знания, умения, навыки

\section{и компетенции.}

Обзор экономической литературы отечественных и, в большей степени, зарубежных авторов позволяет обобщить, выделить и указать основные показатели (рисунок 2). Такие показатели представляют собой объективные данные, на основе которых субъекты хозяйственной деятельности конкурируют в условиях рыночной экономики. Анализ показателей предоставляет возможность управлять и формировать стратегию развития предприятия, с учетом слабых и сильных сторон, выявленных в процессе аналитической работы.

Вопросам обеспечения паритета равных возможностей, имеющих стратегическую цель достижения равновесия и долгосрочной стабильности посвящены труды известных лауреатов Нобелевской премии. К примеру, модели и расчеты представлены в трудах Пола Роберта Милгрома.

С точки зрения процессного подхода, понятие конкурентоспособность, в первую очередь, предприятия представляет собой его способность реализовывать хозяйственную деятельности в соответствии с установленными миссией, стратегическими целями и задачами, а также отражать и противостоять внешним воздействиям. На уровень конкурентоспособности предприятия оказывают влияние различные факторы. В первую очередь, это основные, общие, естественные, специализированные и развитые или искусственно созданные.

Общий список наиболее важных факторов,

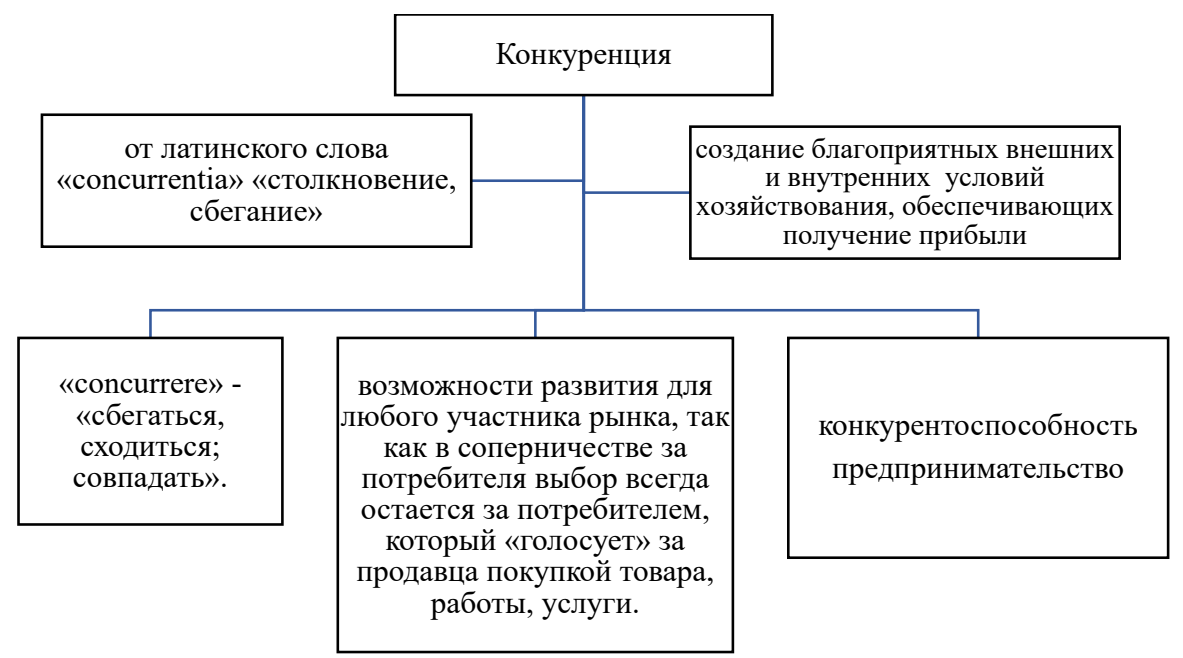

Puc. 1. Этимология понятия «конкуренция» Источник: составлено авторами 

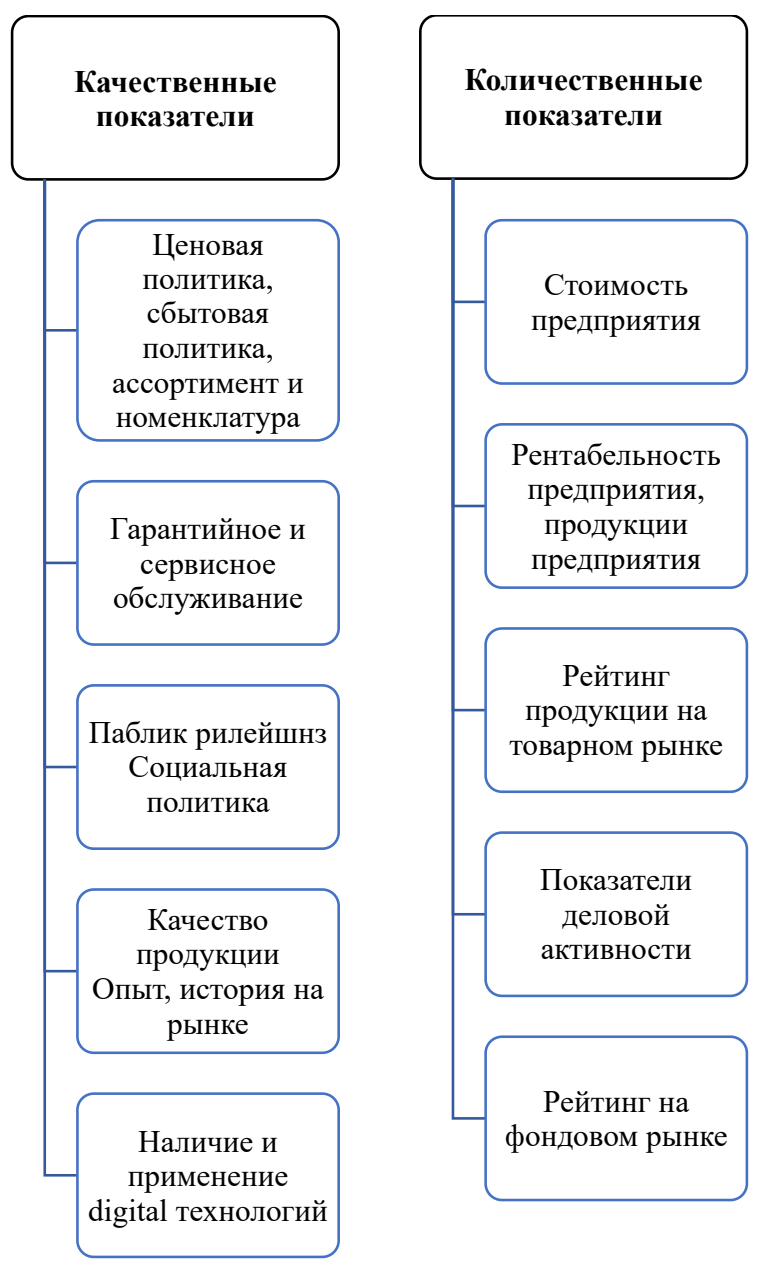

Puc. 2. Комплекс показателей, характеризующих конкурентное положение объекта и субъекта экономики Источник: составлено авторами

влияющих на состояние конкурентоспособности предприятия представлен на рисунке 3. Выделены критерии, исходя из геополитического положения и структуры рабочей силы, наличия качества и количества кадров, научных исследований и технологий, используемых в хозяйственной деятельности, а также качества и количества ресурсной базы.

Для предприятий всех форм собственности в настоящее время становится все более важным не фактическое формирование конкурентоспособности, а управление уже сформированной конкурентоспособностью, налаживание устойчивой и эффективной, стабильной работы по ее укреплению и улучшению.

Отметим, что актуальными являются в профессиональной среде вопросы оценки конкурентоспособности, выявлению лучших методик оценки качественных и количественных показателей.

Управление конкурентоспособностью пер- сонала предприятия представляет собой деятельность, направленную на формирование управленческих решений, которые должны обеспечить сопротивление всем внешним факторам и достичь лидерских позиций, рейтинговых оценок в соответствии с установленными стратегическими целями [5, с. 172]. В то же время управление этим процессом не означает реализацию одного действия для повышения определенной конкурентоспособности бизнеса, а означает целостную систему действий для улучшения всех показателей эффективности бизнеса. Это длительный процесс, требующий больших финансовых вложений и ресурсов, профессионализма менеджеров и специалистов.

Некоторые трудности развития конкурентоспособности субъектов хозяйствования приведены в обобщенной схеме на рисунке 4 . Pешение и учет указанных вопросов возможно приведет к условиям, которые позволят участникам рынка конкурировать с идентичными 


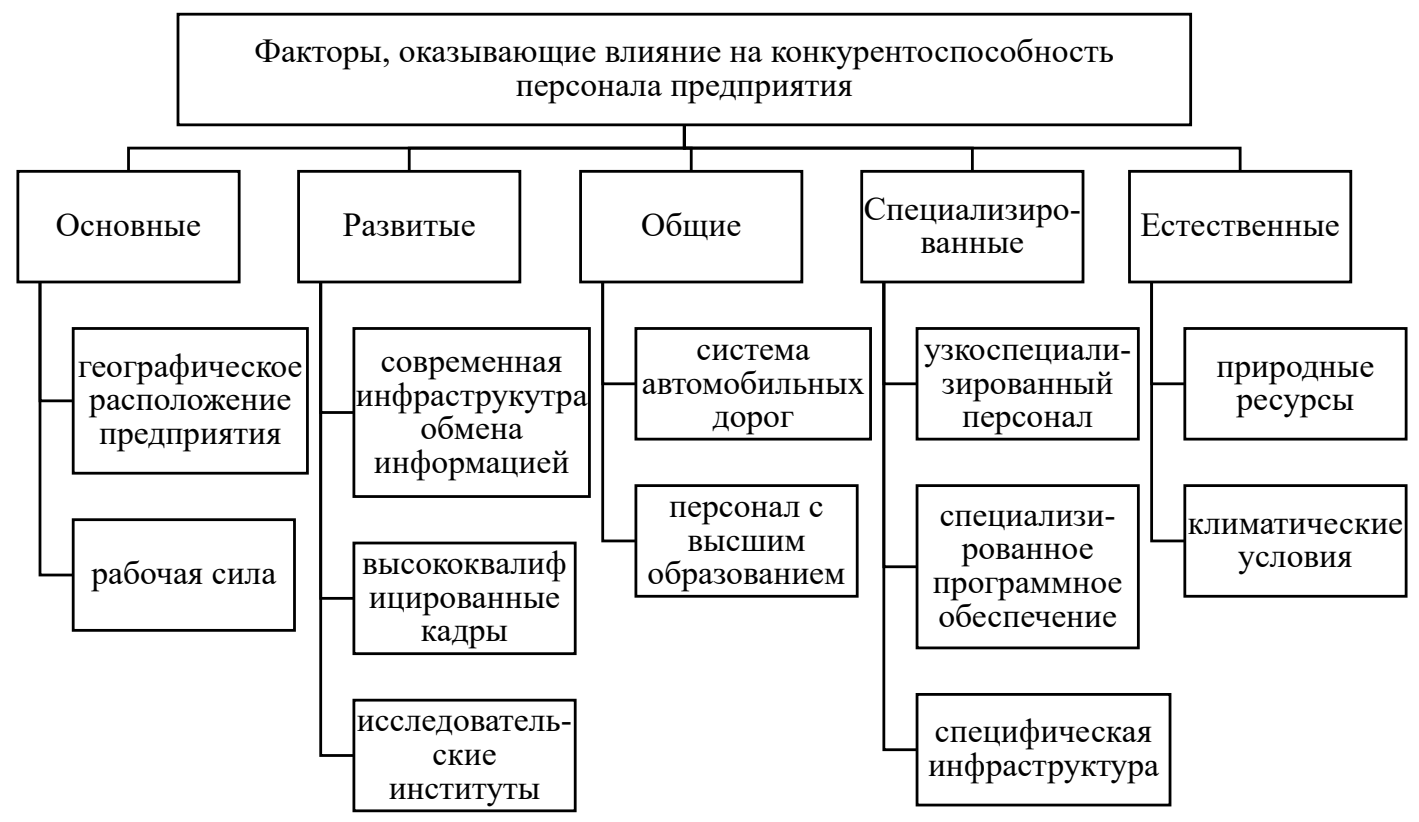

Puc. 3. Факторы, оказывающие влияние на конкурентоспособность персонала предприятия [3, с. 221]

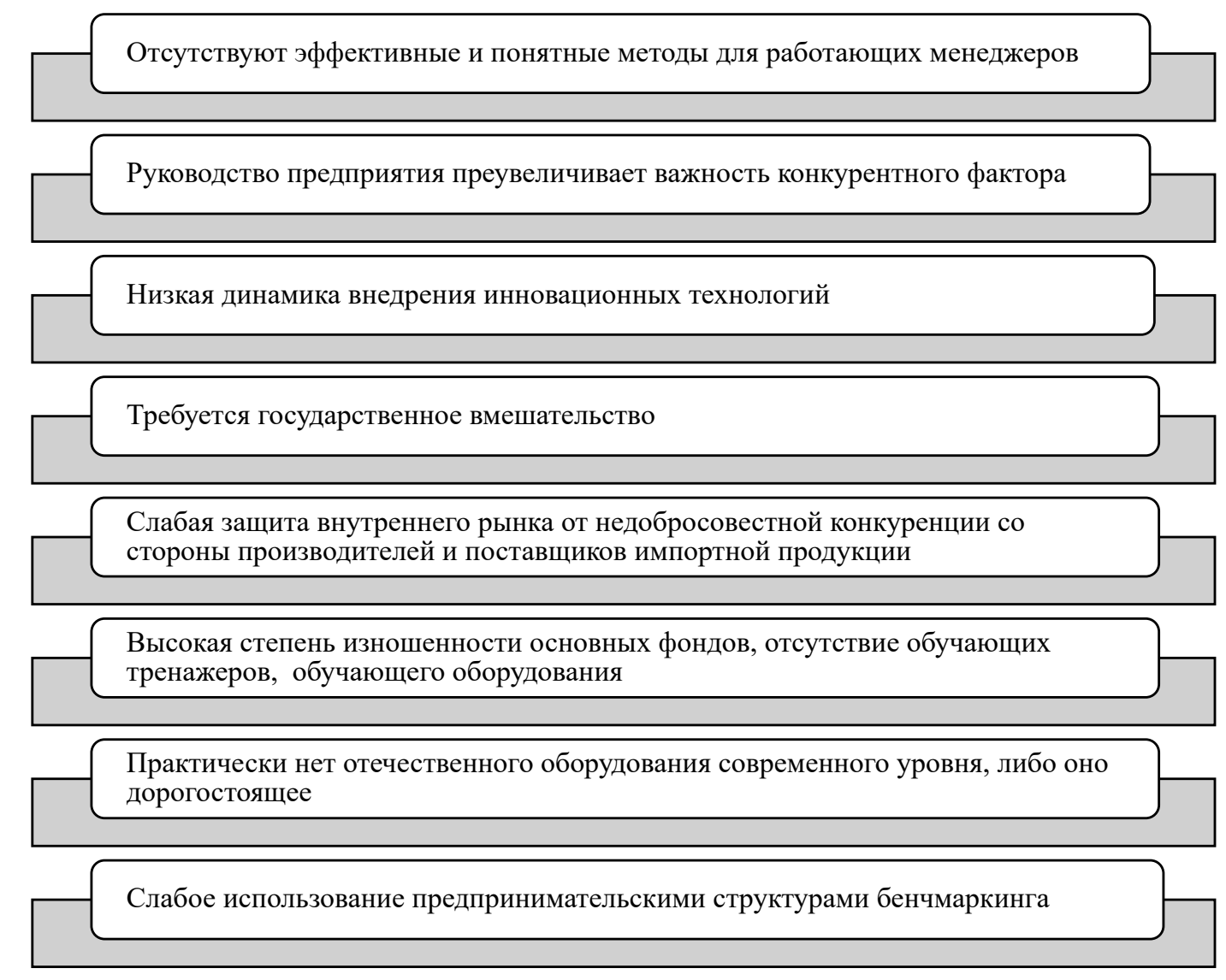

Рис. 4. Ключевые проблемы управления конкурентоспособностью персонала предприятия $[3,5,6]$ 
производителями зарубежных лидеров рынка. Также качество персонала объективно влияет на хозяйственную деятельность организации. Управление персоналом должно быть направлено на повышение как качественных показателей так и количественных показателей конкурентоспособности, что, в свою очередь, должно быть отражено в стратегии развития в части кадровой политики. [6].

В современной практике в управлении приоритет тех или иных затрат определяется рядом количественных показателей, таких как рентабельность, выручка, затраты, в то время как важность качественных показателей недооценивается. Лица, принимающие решения (далее ЛПР), должны в первую очередь, сосредоточиться на всех конкурентных факторах, учитывать их одновременно, принимая во внимание взаимозависимость.

Интересными для анализа с точки зрения прикладной практики, являются современные труды лауреатов Нобелевской премии. Американский ученый экономист, профессор Стенфордского университета, лауреат Нобелевской премии 2020 года Пол Роберт Милгром вместе с Робертом Уилсоном приводят в трудах различные примеры конкурентной борьбы, а также феномен так называемого «победителя» в статье «Auctions and Bidding: А Primer». Авторы подчеркивают важность точных расчетов при реализации конкурентной политики организации, в частности, в части оценки всех затрат.

В опубликованной работе, приводятся на примерах аргументированные функциональные зависимости, доказывающие увеличение объемов выручки и продаж, в зависимости от увеличения затрат на проводимые аналитические процессы в целях изучения действий и политики конкурентов. Макафи и Макмиллан (McAfee and McMillan, 1987) тщательно исследуют как теоретическую, так и эмпирическую литературу об аукционах. Милгром (1987) исследует связи между аукционами и торгами и дает точный математический расчет принципа связи. Также можно выделить исследование Уилсона 1987 года, в котором представлены корреляционные зависимости между аукционными исследованиями и исследованиями рыночных механизмов, в условиях олигополистической конкуренции. Большая часть работ в области экспериментальной экономики сосредоточена на проверке теории аукционов. Также интересные и полезные иссле- дования в области изучения конкурентных позиций и управления конкурентоспособностью, которые можно найти в работах Plott и Smith (1982 г.).

Исследования олигополистической конкуренции в работах Дж.Дж. Стиглера, известного американского ученого и профессора Чикагского университета и Колумбийского университета позволяют констатировать аргументированное доказательство необходимости и возможности управления конкурентоспособностью участника рыночной экономики. Ученый был удостоен Нобелевской премией по экономике еще в 1982 году «за новаторские исследования промышленных структур, функционирования рынков, причин и результатов государственного регулирования» [1-4].

В истории экономической мысли теория совершенной конкуренции была сформирована еще в 1871 году. Одно из самых ранних исследований конкурентной борьбы было проведено Лоуренсом Фридманом (1956). Автор утверждал, что нужно, в первую очередь, изучить прошлое поведение своих конкурентов, чтобы обнаружить закономерности, которые управляли их проводимой конкурентной политикой. Все данные являются результатами эмпирических исследований, что несомненно подтверждает ценность выводов.

В условиях кризиса самое важное значение придается кадрам, их подготовке и повышению квалификации, чтобы организация при минимальном количестве сотрудников смогла сохранить эффективность своей работы.

Международная сеть компаний в области консалтинга и аудита PwC отмечает, что организации, для которых приоритетным направлением является развитие навыков сотрудников и инвестирование в их подготовку и повышение квалификации, не просто становятся более конкурентоспособными, а уверенно опережают конкурентов и обладают более позитивным взглядом на будущее развитие компании.

Как известно, объем знаний в век информационных технологий стремительно меняется, не всегда знания являются актуальными и востребованными. Для удовлетворения потребностей предприятия в трудовых ресурсах необходимо, чтобы их уровень компетенции соответствовал условиям и быстро меняющимся профессиональным стандартам. Нужно принимать во внимание, что при обучении взрослых людей учи- 
тывается уровень физического и психического состояния. Перед организациями стоят задачи поиска таких методов повышения обучения и повышения квалификации, которые сумели бы максимально развить сотрудников с минимальными капиталовложениями.

Возникает вопрос, как выстроить эффективную и работающую систему повышения конкурентоспособности трудовых ресурсов в современных условия. Актуальность данного вопроса подтверждается некоторыми данными, проведенными международной сетью компаний PwC в 2020 году до распространения пандемии коронавирусной инфекции. Статистические данные по результатам опроса приведены в таблице 1 [8].

Следует принимать во внимание также при работе с персоналом о применении индивидуальных подходов к сотрудникам, мониторинге, обновлении и обратной связи при реализации программ подготовки и повышения квалификации. Внутреннее обучение лучше сочетать с внешним, сотрудничать с ведущими вузами. Применение онлайн-платформ, дистанционных курсов позволяет сделать обучение доступнее и экономит ресурсы компании.

Актуальность исследования заключается в том, что мероприятия по повышению конкурентоспособности персонала дают возможность повысить трудовой потенциал работников и, соответственно, производительность, улучшают способность адаптироваться к постоянно изменяющимся условиям, а значит, позволяют стать организациям более конкурентоспособными [3].

Для разработки эффективной системы по- вышения конкурентоспособности персонала в современных условиях возможны к реализации ряд мероприятий.

Во-первых, привлечение к обучению образовательных структур, соответствующим общепринятым стандартам и прошедшим аккредитации для обеспечения подготовки специалистов высокого уровня;

Во-вторых, создание мотивирующей среду, стимулирующих программ для персонала, способствующих и формирующих желанию обучаться, самообразованию и саморазвитию;

В-третьих, создание обучающего центра в организации;

В-четвертых, постоянное обновление образовательных программ внутри организации с целью гибкого реагирования на изменения в экономике;

В-пятых, использование трендовых современных методов в организации обучения.

Стратегия повышения управления конкурентоспособностью предприятий является постоянной важнейшей задачей современного этапа рыночной экономики. Следует также отметить, что повышение конкурентоспособности на микроуровне, то есть на уровне определенных предприятий, должно поддерживаться эффективными методами государственного регулирования. Вышеизложенное позволяет сделать вывод о том, что конкурентоспособность трудовых ресурсов опирается на реализацию мероприятий как со стороны предприятия, так и обеспечение реализации государственной политики в области труда и занятости.

Таблица 1. Данные о результатах опроса среди ЛПР по вопросам повышения качества персонала с применением образовательных технологий.

\begin{tabular}{|l|l|}
\hline \multicolumn{1}{|c|}{ Респонденты } & \multicolumn{1}{c|}{ Результаты } \\
\hline $74 \%$ организаций & $\begin{array}{l}\text { Постоянно видят проблему качества персонала, нехватки квалифицированных } \\
\text { кадров }\end{array}$ \\
\hline $30 \%$ руководителей & $\begin{array}{l}\text { Убеждены в эффективности программ подготовки и повышения квалифика- } \\
\text { ции в целях повышения производительности труда персонала }\end{array}$ \\
\hline $30 \%$ руководителей & Отметили ускорение процесса цифровизации \\
\hline $28 \%$ руководителей & $\begin{array}{l}\text { Реализованные программы в рамках системы подготовки и повышения квали- } \\
\text { фикации положительно отразились на динамике привлечения новых }\end{array}$ \\
\hline $28 \%$ руководителей & $\begin{array}{l}\text { Обучение сотрудников в организациии поспособствовали снижению текучести } \\
\text { кадров, то есть, стало проще осуществлть политику по удержанию высококва- } \\
\text { лифицированных кадров }\end{array}$ \\
\hline
\end{tabular}




\section{Библиографический список}

1. Аксенов И.А., Валеева Ю.С., Галимова Э.И., Демьянова О.В., Дюдина О.В., Жуков А.С., Захаров С.В., Казначевский Б. А., Макарова Е. С., Никифоров О.А., Нечитайлов А.С., Николаев М.В., Романова Т. Е., Саубанов К. Р., Сербиновский Б. Ю., Султанова Д.Ш., Тесленко И.Б., Тимошенко О.В., ТкачА. В., Фахрутдинова Е.В. и др. Факторы повышения конкурентоспособности региона // Казань, 2018. - 300с.

2. Аксенов И.А., Валеева Ю.С., Галимова Э.И., Демьянова О.В., Дюдина О.В., Жуков А.С., Захаров С.В., Казначевский Б.А., Макарова Е.С., Никифоров О.А., Нечитайлов А.С., Николаев М.В., Романова Т. Е., Саубанов К. Р., Сербиновский Б. Ю., Султанова Д.Ш., Тесленко И.Б., Тимошенко О.В., Ткач А. В., Фахрутдинова Е.В. и др. Факторы повышения конкурентоспособности региона / Коллективная монография / Казань, 2018. Том 2. -238с.

3. Егоршин А. П. Эффективный менеджмент организации / А. П. Егоршин. - Москва: ИНФРА-М, 2020. - 388 с. C. 55-56.

4. Лотарева К. М. Основные проблемы управления конкурентоспособностью предприятия / К. М. Лотарева // Экономика и современный менеджмент: теория, методология, практика. - 2018. - С. 220-223.

5. Маруха В.Р. Проблемы обеспечения конкурентоспособности предприятия / В.Р. Маруха // Агропродовольственная экономика. - 2019. - С. 52-56.

6. Соколова М.В. К проблеме управления конкурентоспособностью предприятий в России / М. В. Соколова // Современный менеджмент: проблемы, анализ тенденций, перспективы развития. - 2019. - С. 172-175.

7. Шаповал В.В. Проблемы повышения конкурентоспособности предприятия в современных условиях [Электронный ресурс] / В.В.Шаповал // Материалы ХІ Международной студенческой научной конференции «Студенческий научный форум». - 2019. - Режим доступа: http://scienceforum.ru/2019/article/2018010959.

8. PwC: 74\% руководителей глобальных компаний заявляют о нехватке квалифицированных кадров / Официальный сайт PwC в России. URL: https://www.pwc.ru/ru/press-center/2020/rukovoditeli-kompaniy-zayavlyayuto-nekhvatke-kadrov.html (дата обращения: 09.12.2021)

9. Winners of the Nobel Prize for Economics (англ.). Encyclopædia Britannica. Дата обращения: 20 января 2020 г. (англ.) 